\title{
Tecnología en movimiento
}

\author{
Salvador Cabedo
}

En la actualidad, todos los ciudadanos somos conscientes de estar metidos de lleno en una nueva cultura que ha surgido a consecuencia de la ya reconocida y denominada revolución digital. Así como los progresos científicos de los siglos XVII y XVIII dieron lugar a la Revolución Industrial, el desarrollo y la implantación universal de las tecnologías de la información y la comunicación han dado lugar a la cibercultura o revolución digital, que incide de modo importante en la vida de las personas, y presagia incalculables consecuencias para la historia de la humanidad. Adquirir, manejar, comprender y difundir la información a través de los nuevos procesos tecnológicos constituye una dimensión muy importante en la vida del ser humano. El transistor, el circuito integrado, el ordenador personal, las redes de telecomunicaciones, internet, los móviles inteligentes, etc., han transformado radicalmente la manera en que los seres humanos se relacionan entre sí. Mediante el uso compartido de estos dispositivos tecnológicos se ha establecido una nueva modalidad de expansión de la información que enriquece la capacidad intelectiva del ser humano y permite además una comunicación más universal.

Las tecnologías de la información y la comunicación se han impuesto socialmente y cada día están más presentes en la manera de aprender, comunicar y configurar las diversas relaciones sociales. Las personas hemos ido adquiriendo nuevos hábitos y maneras de comportarnos, hemos incorporado a nuestras vidas el ordenador y los teléfonos inteligentes para adquirir mejor información y poder transmitir ya sea de forma real o virtual nuestros conocimientos. Esta nueva cultura nos sitúa también ante un novedoso panorama personal y social que va más allá de las herramientas tecnológicas que nos rodean y se nos presentan como las protagonistas de nuestro momento histórico. Pero si bien es verdad que no debemos ni podemos mantenernos anclados en una interpretación de la realidad humana que no incorpore las aportaciones de la ciencia y de la técnica, no hemos de confundir el progreso de la humanidad con el simple desarrollo de la investigación científica. Se trata no solo de incorporar y dominar los nuevos objetos simbólicos, mediante los cuales se configuran distintas maneras de vivir, sino de mantener al mismo tiempo una actitud crítica que nos mueva al convencimiento de que el desarrollo científico y tecnológico solo son positivos si redundan en beneficio de la dignidad humana y de la calidad de vida.

Internet se ha colado definitivamente en nuestras vidas y se ha integrado plenamente, con más o menos destreza, en las rutinas de la mayoría de los españoles. Vivimos en hogares que cada vez están más y mejor conectados informáticamente y organizamos nuestra vida sirviéndonos de la ayuda que proporcionan los recursos tecnológicos como los móviles inteligentes y las apps. En la sociedad del conocimiento, la digitalización se nos presenta como un proceso muy positivo e imparable, pues la información tecnológica y la dimensión humana se consideran convergentes y dialécticamente relacionadas. En la sociedad del conocimiento se acortan las distancias entre los pueblos y sus culturas, y se suprimen los siniestros aislamientos y las fronteras. Actualmente es mucho más fácil acceder a la información adecuada para responder a las urgencias ambientales y cumplir mejor nuestros deberes sociales. 
La eficacia de los recursos tecnológicos facilita el desarrollo sostenible para todos los pueblos y posibilita la colaboración social entre ellos.

Según el Informe Sociedad de la Información en España 2014, editado por la Fundación Telefónica, nuestro país es de los más "conectados" de Europa: 8 de cada 10 móviles son smartphones y el $78 \%$ de los internautas son usuarios intensivos. En 2014 se han consolidado e intensificado las tendencias que se presentaban en informes anteriores como proyectos de futuro, y se han producido avances muy significativos en la vida digital de los ciudadanos. Así, ya son 26,25 millones de españoles los que acceden regularmente a internet, 1,45 millones más que en 2013. De ellos, 20,6 millones se conectan diariamente, es decir, el $78 \%$ del total viven conectados. Cabe recordar que solo hace dos años, eran 6 millones de españoles. Y por primera vez, el $50 \%$ de las personas entre 55 y 64 años son usuarios intensivos que acceden diariamente a internet, de modo que conforman la franja de edad que más creció el pasado año (8,6 puntos porcentuales).

Los recursos tecnológicos disponibles en la actualidad no solo pueden servir de ayuda para que los ciudadanos adquieran más y mejores conocimientos, sino que además facilitan su inclusión y participación social. Gracias a la virtualidad de internet y con la ayuda de un ordenador o un dispositivo móvil, las personas nos podemos comunicar con otras personas desde cualquier lugar del planeta y en cualquier momento del día, así como gestionar en tiempo real documentación y servicios de manera cooperativa hasta cotas impensables hasta hace muy poco tiempo. Es importante mencionar que las personas que se conectan a la red acceden ciertamente a más información, pero mantienen al mismo tiempo la capacidad de difundir críticamente su asentimiento o descontento, con lo que pueden intervenir en el análisis crítico de los contenidos transmitidos por la red.

Las nuevas tecnologías están incidiendo firmemente en las formas de trabajar, de educar, de divertirnos, de relacionarnos y de percibirnos a nosotros mismos. Los estudiosos pueden disfrutar de instrumentos y sistemas formativos que complementan la educación presencial, y amplían sus posibilidades mediante las llamadas aulas virtuales, que permiten la educación en línea a través de redes informáticas. Los sistemas asincrónicos de comunicación mediada por ordenador proporcionan a las personas con dificultades para asistir regularmente a la educación pre- sencial establecida nuevas posibilidades y caminos para sustituirla por otra más flexible. Es, por lo tanto, muy lógico que el dominio de las nuevas tecnologías se haya convertido en indispensable no solo para la gente joven, que tiene ante sí un mundo muy abierto, sino también para todas las personas, que necesitan el reciclaje tecnológico para poder mantener el deber personal y social del aprendizaje permanente a lo largo de la vida.

Las personas mayores constituyen un colectivo especialmente significativo en la sociedad actual, pero también con sus riesgos y dificultades. Uno de los peligros anunciados consiste en la llamada brecha digital, que afecta a los grupos de ciudadanos más frágiles socialmente, entre los que se encuentran las personas mayores. Es responsabilidad de todos apoyar la alfabetización digital de los mayores, facilitando el acceso al uso inteligente y útil de las nuevas tecnologías. Este uso debe fomentarse a través de diferentes acciones multidisciplinares y en muy diferentes perspectivas: ámbitos educativos y formativos, políticas de integración social, proyectos de investigación, etc. Con ello se potenciará el capital social y humano de nuestra sociedad.

La realización de las IV Jornadas Internacionales de Mayores y Nuevas Tecnologías, cuyas actas podemos leer y disfrutar en esta publicación, constituye una prueba fehaciente del compromiso de la Universitat Jaume I en la formación de todos los segmentos sociales de su entorno, en especial de las personas mayores. Una vez más, se puede constatar con satisfacción cómo el Programa Sénior «Universitat per a majors» está cumpliendo con su objetivo de promocionar la formación permanente a lo largo de la vida.

Agradecemos la colaboración prestada por los ponentes, nacionales e internacionales, que no solo participaron en las Jornadas, sino que han aportado generosamente el contenido de sus ponencias y comunicaciones para que puedan ser publicadas. Valoramos con gran satisfacción la respuesta por parte de los alumnos, que, además de asistir y participar abundantemente en el desarrollo de los seminarios y ejercicios prácticos, enriquecieron con sus experiencias y matices el contenido de las lecciones magistrales. Apreciamos el importante apoyo que hemos recibido de autoridades académicas y políticas para poder llevar a cabo la realización de estas Jornadas. Queremos también reconocer la excelente colaboración prestada por las personas que trabajan en nuestro Servicio de Comunicación y Publicacio- 
nes, cuya profesionalidad ha sido la mejor garantía para la cuidadosa edición de las actas. A todas las personas que directa o indirectamente han contribuido al éxito de las Jornadas y que además apoyan los objetivos de nuestro Programa Sénior queremos, una vez más, decirles que les agradecemos su apoyo y seguimos confiando en su importante y generosa ayuda. 